\title{
Contribution to the Understanding of Secondary Pyrolysis of Biomass-Based Slurry under Entrained-Flow Gasification Conditions
}

\author{
Philipp Stoesser, ${ }^{\dagger}$ Johannes Ruf, ${ }^{\ddagger}$ Rajender Gupta, ${ }^{\S}$ Neda Djordjevic, ${ }^{\|}$and Thomas Kolb ${ }^{*, \dagger, \ddagger}$ \\ ${ }^{\dagger}$ Karlsruhe Institute of Technology, Institute for Technical Chemistry, ITC vgt, 76344, Eggenstein Leopoldshafen, Germany \\ ${ }^{\ddagger}$ Karlsruhe Institute of Technology, Engler Bunte Institute, Fuel Technology, EBI ceb, 76131, Karlsruhe, Germany \\ ${ }^{\S}$ University of Alberta, Department of Chemical and Mechanical Engineering, CME, Edmonton, AB, Canada, T6G 1H9 \\ ${ }^{\|}$Technical University Berlin, Institute of Fluid Dynamics and Technical Acoustics, ISTA, 10623, Berlin, Germany
}

\begin{abstract}
The objective of this study was to gain insight into the secondary pyrolysis of biomass based slurry under entrained flow gasification conditions. The focus was set on the types of solid products from secondary pyrolysis, their mechanism of formation, and subsequent conversion behavior. Primary chars and pyrolysis oils from wood and wheat straw were produced in a screw pyrolysis reactor. A suspension fuel (slurry) was prepared composed of primary straw char and straw pyrolysis oil. A drop tube reactor was used to study the secondary pyrolysis of the different fuels at $1200{ }^{\circ} \mathrm{C}$ and $3 \mathrm{~s}$ residence time. The secondary pyrolysis of both chars yielded approximately $60 \mathrm{~m} \%$ of secondary char. While the wood char reactivity was unchanged by the secondary pyrolysis, the straw char showed signs of massive deactivation, which is most likely explained by the loss of catalytic activity. The secondary pyrolysis of both pyrolysis oils yielded approximately $20 \mathrm{~m} \%$ of secondary char and soot. Cenospheres could be identified with diameters close to the initial droplet diameter. Oil cenospheres and soot had similar chemical compositions but showed very different reactivities, which is likely to be explained by their different structures. The secondary pyrolysis of the straw based slurry showed results similar to those of the secondary pyrolysis of oil with primary char particles being embedded in the cenosphere carbon shell. Additional thermogravimetric measurements revealed possible conversion mechanisms of cenospheres from oil and slurry feed.
\end{abstract}

\section{INTRODUCTION}

Entrained flow gasification (EFG) is the most widely employed gasification technology worldwide due to its advantage of producing a tar free syngas at high pressure from a wide range of solid and liquid low grade feedstocks. Nowadays, large scale technical gasification units are almost exclusively realized as entrained flow gasifiers. ${ }^{1}$ The design and optimization of EGF systems is mainly based on extensive practical experience. However, this experience is only available for a limited number of well defined liquid and solid fossil fuels as feedstocks. The process design and optimization for more complex low grade fuels such as biomass based chars, oils, and slurries becomes challenging due to the lack of basic understanding of processes governing these reacting multiphase systems.

The development of a new technology for conversion of residual biomass with low energy density into a liquid fuel via pyrolysis-gasification-gas cleaning-synthesis is the overall objective of the ongoing bioliq project at Karlsruhe Institute of Technology (KIT). ${ }^{2,3}$ The bioliq project is part of the German energy transition process (Energiewende). ${ }^{4}$ The bioliq process is currently under development and being tested at KIT. The pilot scale gasification unit is operated at $5 \mathrm{MW}$ thermal input and a nominal pressure of 40 and 80 bar, respectively. The present paper is associated with the bioliq project and contributes to the mathematical modeling of the entrained flow gasification by providing kinetic data for the conversion of suspension fuels (slurry) under EFG conditions. ${ }^{5-8}$

Especially, the heterogeneous solid conversion needs to be better understood since it is commonly accepted as being the most relevant step for complete fuel conversion in an EFG.
Trying to derive kinetic parameters of practical use, it is not sufficient to only consider the raw fuels themselves. It is mandatory to understand the process based on the specification of the intermediate solids that are formed and converted during entrained flow gasification. For dry solid fuels such as woody biomass and especially coal, this has been done extensively., ${ }^{9,10}$ Also, work was published concerning the potential, properties, and practical application of bioslurry. ${ }^{11-13}$ However, due to the lack of literature on the secondary pyrolysis of biomass based slurry, the motivation of this study was to gain an under standing of the types of intermediate solids created during slurry pyrolysis as well as of their formation and conversion mechanisms.

In the past, the literature and our own research revealed general solid formation pathways of secondary pyrolysis. During the introduction of dry fuels to the harsh environment of an entrained flow gasifier, their chemical and physical characteristics change significantly, leading to solids of almost pure carbon and high surface area, depending strongly on the type of fuel and process conditions applied. Oils introduced to the same process conditions can show the formation of newly created char. ${ }^{14,15}$ In the case of biogenic pyrolysis oils, this can mainly be attributed to the polymerization of highly reactive unsaturated organic components. Known in the literature, pyrolysis oils undergo four stages during heat up: (1) thickening (water evaporation), (2) phase separation, 


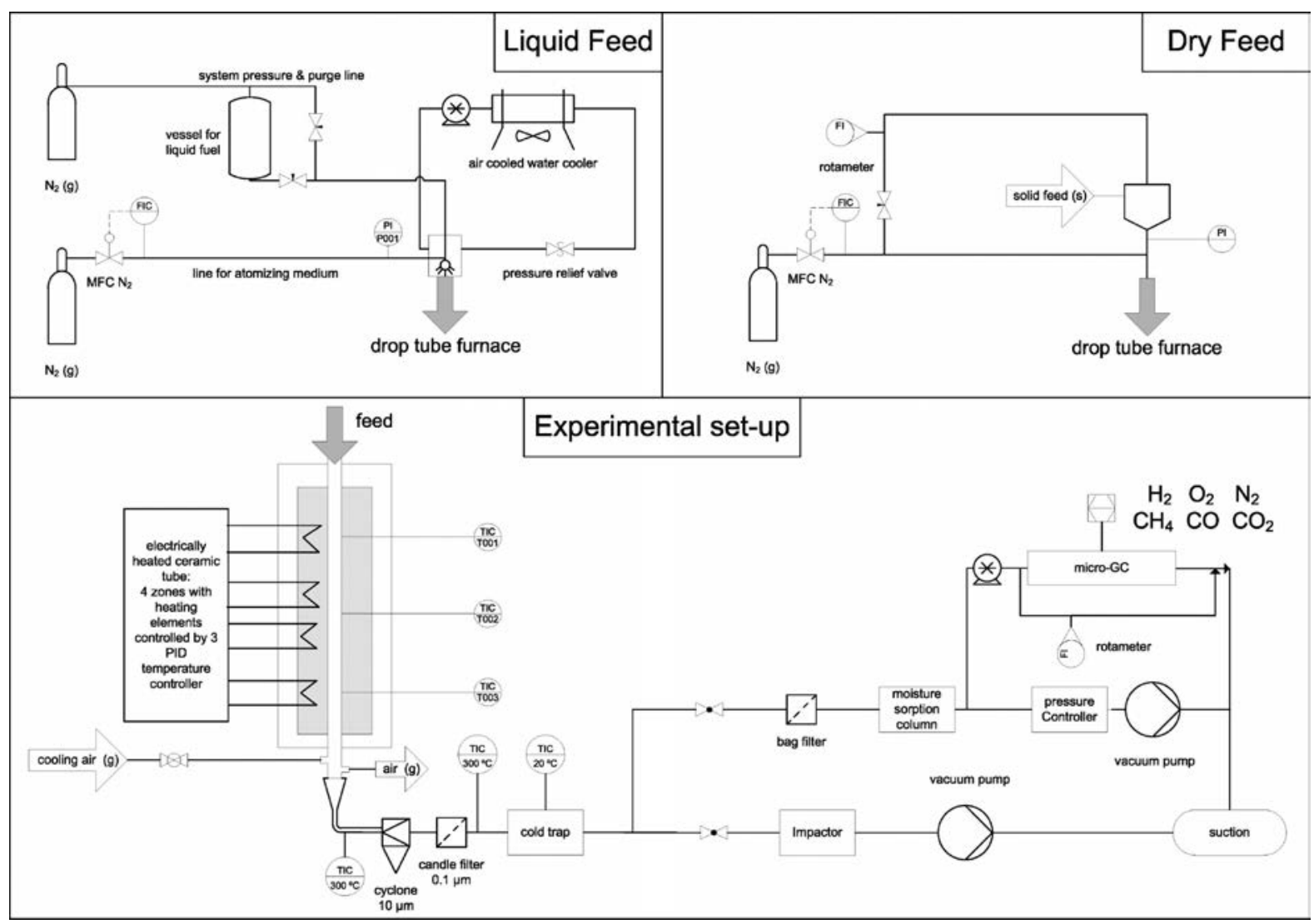

Figure 1. Flow sheet of the drop tube furnace setup.

(3) gummy formation of pyrolytic lignins, and (4) char formation. ${ }^{16}$ In pyrolysis plants, char formation at elevated temperatures is known to cause problems during condensation of tar compounds. The inability to determine satisfactory boiling range data for pyrolysis oils is also linked to the polymerization reactions at elevated temperatures. Also, secondary pyrolysis of pyrolysis oils using thermogravimetric analysis shows noticeable amounts of solid residue. In preliminary experiments, the heat up of a wood derived pyrolysis oil in a differential scanning calorimeter to $500{ }^{\circ} \mathrm{C}$ in nitrogen resulted in a solid yield of approximately $20 \mathrm{~m} \%$ under atmospheric conditions, while increasing the pressure to 40 bar led to a solid yield of approximately $40 \mathrm{~m} \%$. This might be explained by the boiling temperatures of the oils shifting to higher temperatures while the polymerization and cracking reactions still occur at the same temperatures as for atmospheric pressure.

Preliminary estimations from our own experiments suggested that, while gasifying slurry, the solid intermediates of secondary pyrolysis might even contain more material from cracking of the oil phase than secondary char from the fed primary solids. Additionally, besides the aspect of secondary solid yields, an open question remained of how the different types of secondary solids might interact.

Since at the time of writing, there was no literature available on secondary pyrolysis of biogenic suspensions, the motivation was to design an adequate experiment which was able to simulate the conditions of secondary pyrolysis of bio oil slurry under EFG conditions. Following activities of the Helmholtz Alberta Initiative (HAI, www.helmholtz alberta.org), biogenic fuels prepared at KIT (Karlsruhe, Germany) were fed to a drop tube furnace at the University of Alberta (Edmonton, Canada). The resulting secondary solids were then intensively studied at both locations. The approach was to not only study the slurry pyrolysis itself but also run preliminary experiments with dry char and pyrolysis oil separately to be able to gain independent solid yields and to clearly identify the oil-char interactions of slurry pyrolysis. To further gain a more detailed understanding, primary fuels from different biomasses, different drop tube feeding systems, and varying slurry primary char contents were applied.

\section{EXPERIMENTAL SECTION}

Preparation of Primary Fuels. Softwood and wheat straw were chosen as feedstocks, representing forestry and agricultural energy resources with different structures and chemical compositions. The softwood consisted mainly of fir and was practically bark free. The wood chips and chopped wheat straw were milled to particle sizes of around $1 \mathrm{~mm}$ and fed to a screw pyrolysis reactor. The process can be classified as a fast pyrolysis, ${ }^{17}$ and a description of the reactor setup can be found in the literature. ${ }^{18}$ With $500{ }^{\circ} \mathrm{C}$, a temperature well within the typical range of common pyrolysis oil and char production, was chosen for the screw pyrolysis process. The rotational speed of the screw was adjusted to provide an equal solid residence time of $5 \mathrm{~min}$ for both fuels. Vapor residence times at pyrolysis temperature were approximately $1 \mathrm{~s}$.

The produced solids were weighed, and condensable gases were condensed in a water cooled plate condenser. Permanent gases were metered, and their composition was measured before being burnt in a flare. The liquid mixture was given time to separate into water soluble and water insoluble phases. The liquids further referred to as primary pyrolysis oils were the water insoluble fractions.

The primary chars were crushed in a blade granulator and sieved to obtain particle fractions between 50 and $75 \mu \mathrm{m}$. Their chemical and 
physical properties are shown in the Results and Discussion section along with the secondary fuels.

The characterization of the primary chars via energy dispersive $\mathrm{X}$ ray spectroscopy (EDX) showed that, besides carbon and oxygen, the primary straw char also contains a high content of potassium, chlorine, and calcium. Alumina was only found in small quantities in areas of high calcium and potassium content. No noticeable nickel or iron concentrations were found on the char surfaces. The concentrations of alkaline and alkaline earth metals (AAEM) found on the surfaces of the primary wood char were significantly smaller compared to those found in the straw chars. The most noticeable concentrations were also those of potassium and calcium.

Although already being very low in solids, the primary oils were filtered through a $2 \mu \mathrm{m}$ metal sinter filter prior to further application. Filtering was carried out to ensure that no particulate matter was introduced into the secondary reaction system. This was crucial since the desired study of solids formed by the oil required that no solids were present in the feed.

To further characterize the pyrolysis oils, data on calorific value, viscosity, heat capacity, surface tension, and density were generated. Values for both oils were well within the range reported in the literature. $^{19-23}$ The chemical properties of all fuels are shown in the Results and Discussion section along with those of the secondary fuels (see Tables 1 and 3 ).

A slurry consisting of primary straw char and its corresponding straw derived oil was mixed with a solid mass fraction of $5.8 \mathrm{~m} \%$. The viscosity, surface tension, and density measured were similar to the values in the case of pure straw oil.

Setup of Secondary Pyrolysis Experiments. The used drop tube furnace setup (Figure 1) is described in detail in the literature. ${ }^{24}$ It mainly consisted of an electrically heated mullite tube with an inner diameter of $64 \mathrm{~mm}$ and a length of $1500 \mathrm{~mm}$. The length of the isothermal zone was measured to be approximately $1.0 \mathrm{~m}$ for all following experiments. To separate particles for external analysis, a cyclone and a candle filter with extremely high separation efficiency were used. Since condensation of condensable hydrocarbons on the surfaces of the collected solids was expected, both cyclone and candle filter were heated to temperatures between 300 and $350{ }^{\circ} \mathrm{C}$ well below $400{ }^{\circ} \mathrm{C}$ to limit dehydration reactions forming solids. This temperature range is commonly accepted by the literature. ${ }^{25,26}$ A cold trap was used in order to condense water and heavy hydrocarbons from the hot product stream as well as to provide gas cooling. A MicroGC Varian CP 4900 measured the concentration of the gas components $\mathrm{N}_{2}, \mathrm{CO}_{2}$, $\mathrm{CO}, \mathrm{H}_{2}$, and $\mathrm{CH}_{4}$. Noncondensable hydrocarbons larger than methane could not be detected with this setup. A vacuum pump and pressure controller were used to adjust the gauge pressure inside the reaction tube to be slightly positive in order to avoid excess air. During experiments, the gauge pressure was approximately 3-7 mbar.

The solid feed was dosed by a Schenck AccuRate M0D106 volumetric feeder with pulsating walls, and a flight free auger was introduced to the reactor in a nitrogen gas flow.

For all oil and slurry feed experiments, a pressurized stainless steel vessel was used to feed the liquids to the applied nozzles described below. Flow rates were calibrated by adjusting a fine valve and were cross checked after each experiment by total mass balance of the feed vessel. In order to protect the pyrolysis oil from the radiation heat that would cause undesired evaporation, polymerization, and cracking at the nozzle tips, the nozzles were mounted within a water cooled jacket. Two different nozzles were used for the experiments. To generate a fine spray, a custom made dual fluid nozzle with a liquid channel diameter of $0.5 \mathrm{~mm}$ and an annular gap of $1.8 \mathrm{~mm}$ for the atomizing gas was applied. The nozzle had a design gas velocity of $100 \mathrm{~m} / \mathrm{s}$, while the liquid velocity was calculated to be well below $1 \mathrm{~m} / \mathrm{s}$. Measurements with a Malvern Spraytec laser diffraction spectrometer resulted in Sauter mean diameters (SMD) of $10-15 \mu \mathrm{m}$ for the liquid feed experiments with this nozzle. The second nozzle was built according to the feeder design of the past studies that fed asphaltenes to the drop tube furnace. ${ }^{27}$ It consisted of a liquid channel diameter of $1.7 \mathrm{~mm}$ and an annular gap of $1.4 \mathrm{~mm}$ for the atomizing gas. Spraytec measurements with this nozzle were not reliable due to an insufficient droplet number density. However, in high speed images, it was clearly visible that droplet sizes were significantly larger than the ones of the first nozzle and also showed a wider range. The SMD can be assumed to be in the order of $500 \mu \mathrm{m}$.

Experimental Matrix. Three different sets of experiments were carried out. Dry feed experiments applying primary wood and straw chars, liquid feed experiments applying wood and straw oils, and slurry feed experiments applying the straw char-straw oil slurry described above.

For all experiments, a fuel feed rate of $2 \mathrm{~g} / \mathrm{min}$ was chosen. The volume flow of nitrogen was adjusted to achieve a gas residence time of around $3 \mathrm{~s}$ inside the isothermal zone for all experiments. Dilution by volatiles and the resulting change in gas residence time were largely accounted for by correcting the nitrogen gas flow according to the volatile gases detected by the gas chromatograph (GC). The remaining inaccuracy in residence time is expected to be in the range of $\pm 10 \%$ and is not considered crucial to this investigation. Although temperature variations were also carried out, the presented data are limited to $1200{ }^{\circ} \mathrm{C}$ for all experiments. For the liquid feed experiments, a variation of droplet sizes was carried out applying oils with both the small and the large SMD nozzles. Slurry was atomized utilizing the large SMD nozzle.

After the system reached steady state under nitrogen flow, fuel was introduced to the reactor. While the solid products from primary char were mainly collected by the cyclone, the candle filter was used to separate practically the entire amount of the produced solids in the case of the liquid feed experiments. The solid samples were left under nitrogen flow until they reached room temperature before they were removed and exposed to air.

Characterization Methods. A Netzsch model 209 F1 Iris thermogravimetric analyzer (TGA) was used to determine moisture, volatile, and ash content as well as $\mathrm{CO}_{2}$ reactivity of all examined solids. Moisture and ash were determined by mild heat up $(5 \mathrm{~K} / \mathrm{min})$ and $2 \mathrm{~h}$ holding time at $105{ }^{\circ} \mathrm{C}$ in nitrogen, followed by mild combustion in $5 \mathrm{v} \%$ oxygen at $550{ }^{\circ} \mathrm{C}$ ramping up to $700{ }^{\circ} \mathrm{C}$ and $21 \mathrm{v}$ $\%$ oxygen. Volatiles were determined by heat up to $900{ }^{\circ} \mathrm{C}(50 \mathrm{~K} /$ $\mathrm{min}$ ) in nitrogen. After a holding time of $15 \mathrm{~min}$, the inert atmosphere was changed to contain $10 \mathrm{v} \% \mathrm{CO}_{2}$. The gasification segment was completed when the mass signal leveled off to constant values again. Using the mass-over time curve, the reactivity of the solid samples at a given time $t$ was calculated according to the literature. ${ }^{28}$ All reactivities reported within this work were calculated at a conversion of $50 \%$ and hence indicated as $r_{\mathrm{m}, 50}$.

Scanning electron microscopy (SEM) was used to gain visual images within the micrometer scale of the outer surface structure of all examined solids. Two modes were used: Secondary electrons (SE) which give information about the topology and morphology of the sample surface, and backscattered electrons (BSE) which are generally used to obtain the qualitative chemical composition at certain points of the sample using energy dispersive $\mathrm{X}$ ray spectroscopy (EDX). It is also known for its ability to penetrate thin layers of the outer surface to some extent. In contrast to the SE imaging mode, solid structures which are thinner than approximately $1 \mu \mathrm{m}$ disappear in the BSE imaging mode. The comparison of both methods was used to identify thin solid layers. A Hitachi model S 2700 with an acceleration voltage of $10 \mathrm{kV}$ was used if not denoted differently. Gold sputter was applied to prepare all samples.

EDX was used for mapping of trace elements such as inorganics. A Philips model XL30 ESEM system was operated with samples which were sputter coated with carbon of a thickness between 15 and $20 \mathrm{~nm}$. The acceleration voltage of the electron beam was $15 \mathrm{kV}$, which resulted in a penetration of approximately 500-1000 nm.

Standard bright field transmission electron microscopy (TEM) was used to gain visual images of the structure of solids which were within the nanometer scale. A Zeiss Omega 922 transmission electron microscope was used, and the acceleration voltage was set to $200 \mathrm{kV}$. Chunks from the filter cake were pulverized mechanically and suspended in acetone from where a few droplets of the suspension were pipetted. Ultrasonic sound atomization created a mist which an 

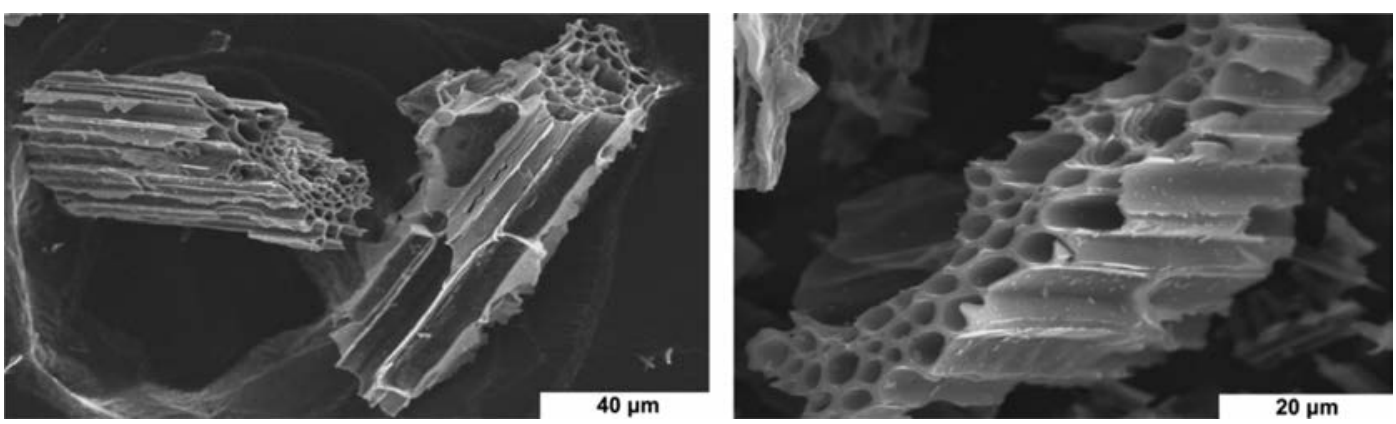

Figure 2. SEM images of straw char. Left: primary straw char; right: secondary straw char pyrolyzed at $1200{ }^{\circ} \mathrm{C}$ and $3 \mathrm{~s}$.

ultrathin copper structure as sample carrier was exposed to. This led to droplet deposition on the carrier's surfaces.

Elemental analysis (EA) was used to obtain a quantitative composition of solid and liquid samples. The main organic components were determined by combustion, oxygen by difference. The ash of selected solids was also analyzed according to DIN 51729 and DIN EN ISO 11885. The water content of the pyrolysis oils was determined by means of Karl Fischer titration (ASTM E203).

Specific surface area measurements of all solids within this study were carried out by five point isothermal adsorption of nitrogen at 77 $\mathrm{K}$ in a Micromeritics ASAP 2020 MP. Samples were degassed at 180 ${ }^{\circ} \mathrm{C}$ and $3 \mu$ bar for $12 \mathrm{~h}$ prior to analysis. Calculation of the corresponding specific surface areas was done applying the multipoint Brunauer, Emmett, and Teller (BET) method according to ISO 9722 and DIN 66131.

\section{RESULTS AND DISCUSSION}

Within this section, first, the results of the three different types of drop tube experiments with dry, liquid, and slurry feed are discussed individually. Besides presenting solid and liquid yields as well as gas compositions, the focus is set on characterization of the generated secondary solids. Various chemical and physical properties are discussed in order to better understand the formation and nature of the respective solid types. At the end of this section, focus is set on the subsequent conversion of the generated secondary solids. A comparative gasification study reveals new insight on how the different classes of secondary solids behave in gasifying atmospheres.

Dry Feed Experiments. From the dry feed experiments, approximately $60 \mathrm{~m} \%$ of fed solids could be recovered from both fuels (primary wood and straw chars), respectively. The solids consisted purely of secondary char. No soot, water, or tar was found. For both fuels, the gaseous products consisted of around $30 \mathrm{v} \% \mathrm{CO}, 2 \mathrm{v} \% \mathrm{CH}_{4}$, and the rest was $\mathrm{H}_{2}\left(\mathrm{~N}_{2}\right.$ free, dry basis). These results are comparable to the fast pyrolysis of wood particles in similar systems reported in the literature, ${ }^{29}$ although a much higher soot formation is generally reported if the primary solid is raw biomass that still contains most of its volatiles.

Figure 2 shows SEM images of primary and secondary straw char particles. It can be seen that there are no major changes of the particle structure in the microscale. The only noticeable minor changes were found at edges which appear to be slightly rounded off after secondary pyrolysis. Wood char showed the same behavior as straw char.

The elemental analysis of primary and secondary chars from dry feed can be found in Table 1 . The organic part of both dry feed fuels was changed in a manner which is considered typical of pyrolysis. While both hydrogen and oxygen contents decrease, the carbon contents increases. Under the selected
Table 1. Elemental Analysis and Ash Contents of Primary and Secondary Chars from Dry Feed

\begin{tabular}{|c|c|c|c|c|c|}
\hline & ash & $\mathrm{C}$ & $\mathrm{H}$ & $\mathrm{O}$ & $\mathrm{N}$ \\
\hline fuel & $\mathrm{m} \% \mathrm{mf}$ & \multicolumn{4}{|c|}{$\mathrm{m} \% \mathrm{maf}$} \\
\hline primary wood char & 3.6 & 83.3 & 3.0 & 10.7 & 0.3 \\
\hline secondary wood char & 4.2 & 98.5 & 0.6 & $<0.1$ & 0.5 \\
\hline primary straw char & 19.2 & 85.6 & 2.7 & 10.4 & 0.7 \\
\hline secondary straw char & 15.7 & 96.5 & 0.5 & $<0.1$ & 1.0 \\
\hline
\end{tabular}

experimental conditions, most of the nitrogen appears to remain inside the secondary chars.

Within this study, the ash content of the secondary wood char increased slightly but the ash content of the secondary straw char did not. During pyrolysis, volatile organic matter is released, which generally leads to a relative increase in ash content. However, in reducing atmospheres at high temper atures thermodynamically, a significant proportion of alkalines is released. A study has shown that biomass ash from primary pyrolysis at $500{ }^{\circ} \mathrm{C}$ suffered a mass loss of $23-48 \mathrm{~m} \%$ during secondary pyrolysis at up to $1300{ }^{\circ} \mathrm{C}$. ${ }^{30}$ Since the straw char investigated in this work was rich in alkalines, this might be an explanation of the observed decreasing ash content of secondary straw char.

Both dry feed fuels experience a strong surface area increase by a factor of 10 and more during secondary pyrolysis (Table 2 ). While the reactivity of the secondary wood char remains

Table 2. Specific Surface Area and Reactivity of Primary and Secondary Chars from Dry Feed

\begin{tabular}{lcc}
\multicolumn{1}{c}{ fuel } & $\begin{array}{c}\text { BET surface area, } \\
\mathrm{m}^{2} / \mathrm{g}\end{array}$ & $\begin{array}{c}\text { TGA reactivity, } r_{\mathrm{m}, 50} \\
10^{-4} \mathrm{~s}^{-1}\end{array}$ \\
primary wood char & 5 & 5.8 \\
secondary wood char & 55 & 5.7 \\
primary straw char & 4 & 13.0 \\
secondary straw char & 41 & 5.3 \\
\hline
\end{tabular}

constant, the reactivity of the secondary straw char decreases by around $40 \%$. From the literature, it is known that the specific surface area increases with increasing heating rates and decreases for higher pyrolysis temperatures and longer residence times. ${ }^{28}$ An increase in specific surface area should also result in an increase in reactivity if the intrinsic reaction rate is constant and no diffusion effects are present. The observed effects, however, may be explained by the solid chemistry changing as well. During secondary pyrolysis, the order of the carbon matrix increases (graphitization), which results in a general decrease in intrinsic reactivity. It can be speculated that the initial specific surface area of primary char 

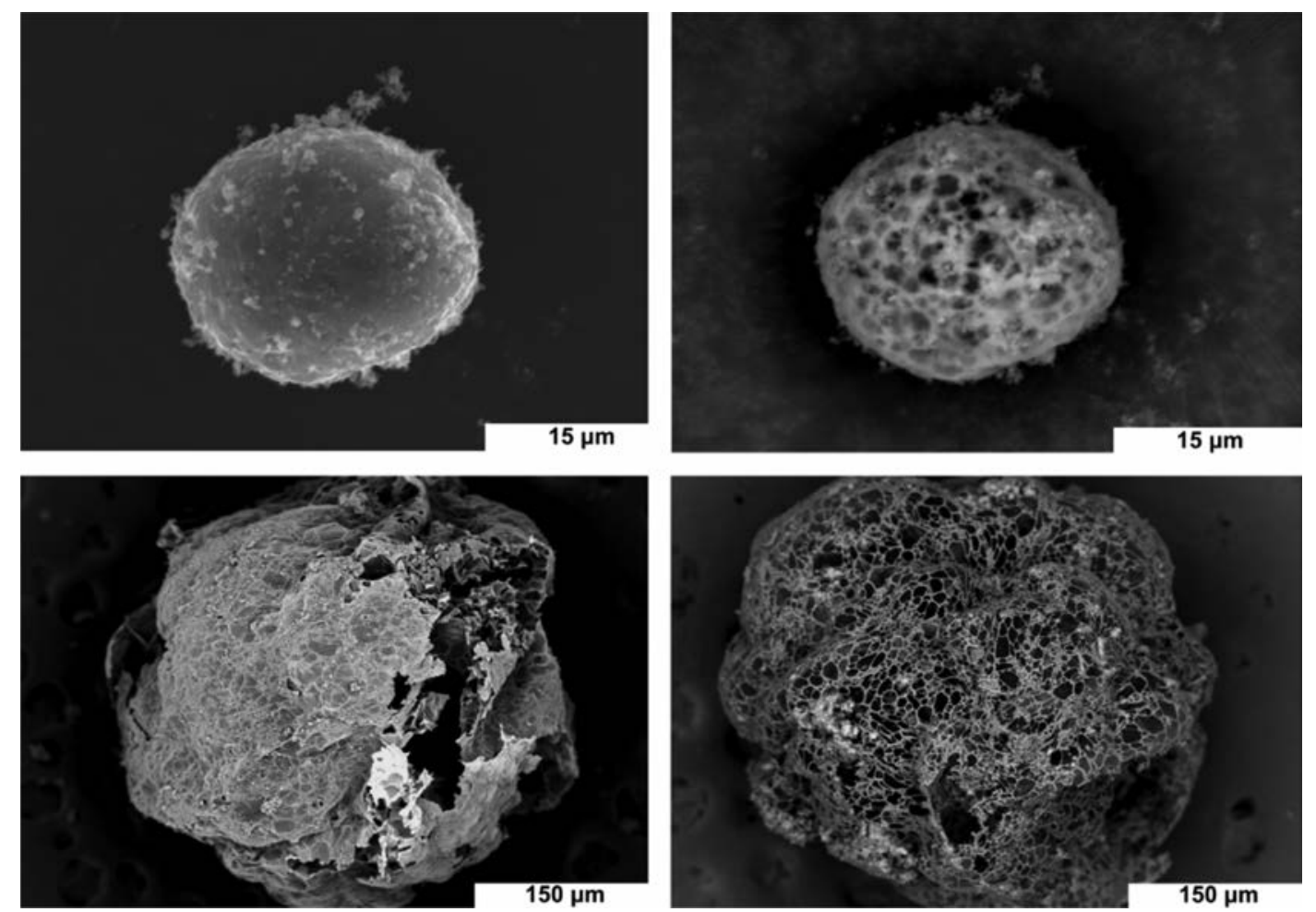

Figure 3. SEM images of straw oil cenospheres. Left: SE imaging mode; right: BSE imaging mode; top: small SMD spray; bottom: large SMD spray.

increases during the Boudouard reaction so that there might be a much higher specific surface area available at $50 \%$ conversion rate (where the reactivity is measured). The fact that the reactivity of solid fuels is not necessarily proportional to their initial total surface area has been observed before and is frequently reported in the literature.

While the reactivity of solid fuels is a function of morphology, order of the carbon matrix, and catalytically active sites, studies have shown that the catalytic effects of the inorganic ash components can have a higher influence on the char reactivity than the surface area. ${ }^{28}$ Especially, potassium is a strong catalyst which is found in high concentrations inside the primary straw char ash. This is a possible explanation of the reactivity of the primary straw char being much higher than the reactivity of the primary wood char.

The catalytic activity of inorganic components like potassium can be greatly reduced by evaporation or thermal deactivation. In the literature, the volatilization of alkalines of biomass ash is shown to start between 800 and $900{ }^{\circ} \mathrm{C}$ and seems to be strongly promoted at temperatures above $1000{ }^{\circ} \mathrm{C} .{ }^{30}$ In this study, wood char ash experienced a decreased potassium content of $18 \%$, while straw char ash experienced a decreased potassium content of $45 \%$ during secondary pyrolysis. Similarly to the ash analysis, EDX of the char surfaces revealed that the potassium content of the straw char decreased significantly with the amounts still present being located in high silica containing areas of the char surface. This effect has been shown before and plays an important role for char reactivity since silicapotassium compounds are reported to be catalytically inactive. ${ }^{31}$ Both the decrease in potassium content as well as the formation of potassium silicates further support the above postulated assumption that the pyrolysis conditions of $1200^{\circ} \mathrm{C}$ for $3 \mathrm{~s}$ were sufficient to significantly reduce the catalytic activity of secondary char.
Liquid Feed Experiments. From the liquid feed experi ments, approximately $20 \mathrm{~m} \%$ of feed could be recovered as solid fraction from both fuels (wood and straw oils). These solids consisted of two different fractions: Spherical secondary char particles and soot. Approximately $1 \mathrm{~m} \%$ of water and 1 $\mathrm{m} \%$ of tar were found inside the cooling trap based on feed. For both fuels, the permanent gases consisted of around $30 \mathrm{v} \% \mathrm{CO}$, $2 \mathrm{v} \% \mathrm{CH}_{4}, 2 \mathrm{v} \% \mathrm{CO}_{2}$, and the rest was $\mathrm{H}_{2}\left(\mathrm{~N}_{2}\right.$ free, dry basis $)$. Similar gas compositions of wood bio oil pyrolysis are reported in the literature. ${ }^{14}$

Figure 3 shows SEM images of secondary char from straw oil. In the literature, ${ }^{32}$ the char from the pyrolysis of liquid fuel droplets is known as cenospheres. Cenospheres are hollow spheres, composed of thin layers consisting mainly of carbon. In Figure 3, the top represents oil cenospheres applying the nozzle with small SMD, while the bottom represents oil cenospheres applying the nozzle with large SMD. Since the SMD of the small nozzle was designed to be around $10-15 \mu \mathrm{m}$ and the recovered oil cenospheres were in the order of 10-25 $\mu \mathrm{m}$, the ratio of cenosphere to droplet diameter of around 1-2 can be derived as observed in the literature. ${ }^{33}$ The large SMD nozzle (approximately $500 \mu \mathrm{m}$ ) produced larger cenospheres which were less spherical and in the size range between 300$600 \mu \mathrm{m}$. In the literature, similar cenospheres from combustion of bio oil ${ }^{34}$ and residual oil ${ }^{32}$ can be found.

The SEM images were created in the SE mode on the left, and in the BSE mode on the right (Figure 3). As described above, BSE is able to penetrate thin layers of material to a depth of approximately $0.5-1 \mu \mathrm{m}$. Applying this to the oil cenospheres clearly shows dark sections, which indicates that the observed particles were indeed hollow. In the case of the large oil cenospheres, a number of fractured spheres were found which were all hollow.

The edges of fractured cenospheres revealed that the thin carbon layers were significantly thinner than $1 \mu \mathrm{m}$ and formed 

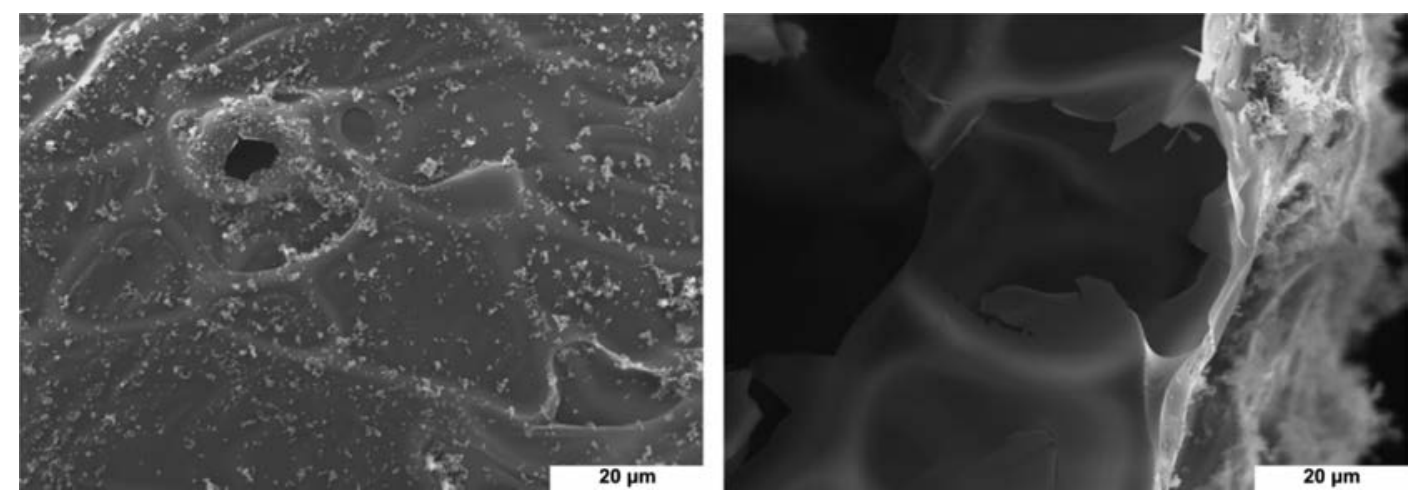

Figure 4. SEM images of a straw oil cenosphere. Left: blowhole; right: edge of a fractured cenosphere (cenosphere outside on right image side).

honeycomb like structures (Figure 4, right). The outer surfaces of the cenospheres were covered with soot aggregates. Whether the soot deposited under reaction conditions or is simply the product of particle collection remains unanswered.

On the outer surface, some of the cenospheres showed so called blowholes (Figure 4, left), which are formed by violent gas release caused by increasing inner pressure at later stages of the solidification of the outer surface. This effect is also known from the literature. ${ }^{32}$

Past studies have shown that soot textures consist of layers of hexagonal face centered arrays on the order of magnitude of single digit nanometers. ${ }^{35}$ Figure 5 shows a TEM image of soot

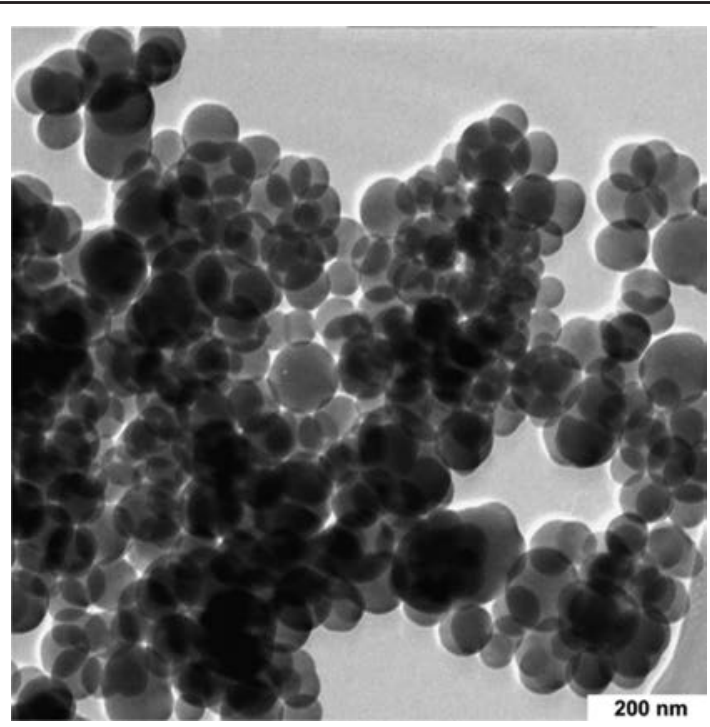

Figure 5. TEM image of straw oil soot.

from straw oil pyrolysis. The average diameter of the spherical particles was around $90 \mathrm{~nm}$. The straw oil soot images were similar to images of soot formed during high temperature pyrolysis of woody biomass. ${ }^{29}$

The chemical composition of the liquid feed and the corresponding solid products are given in Table 3. None of the fuels (feed as well as products) contained an ash content above $0.1 \mathrm{~m} \%$. For pyrolysis oils produced under similar conditions, ash contents of $0.14 \mathrm{~m} \%$ for pyrolysis oil derived from wheat straw and $0.08 \mathrm{~m} \%$ for oil derived from hard and soft wood are reported. ${ }^{19}$ The chemical composition of oil cenospheres produced by wood oil pyrolysis is similar to the one produced by straw oil pyrolysis. Oil cenospheres and oil soot mainly
Table 3. Elemental Composition of Primary Oils and Secondary Solids from Liquid Feed Experiments

\begin{tabular}{lcccrrr}
\multicolumn{1}{c}{ fuel } & $\begin{array}{c}\text { moisture } \\
\text { m\% }\end{array}$ & \multicolumn{4}{c}{$\mathrm{C}$} & \multicolumn{2}{c}{$\mathrm{O}$} & $\mathrm{N}$ \\
m\% maf & \\
primary wood oil & 12.7 & 65.9 & 6.7 & 27.0 & 0.6 \\
wood oil cenospheres & & 97.4 & 1.9 & 0.6 & 0.3 \\
primary straw oil & 16.7 & 70.1 & 7.3 & 21.7 & 1.2 \\
straw oil cenospheres & & 97.6 & 1.7 & 0.5 & 0.3 \\
straw oil soot & & 98.2 & 1.2 & $<0.1$ & $<0.1$
\end{tabular}

consist of carbon and low amounts of hydrogen. While the oil soot is free of oxygen and nitrogen, the oil cenospheres contain small amounts of these elements. This indicates that the cenospheres were formed by liquid phase cracking of heavy tar components still showing traces of elements of the former oil while the oil soot particles were polymerized components from the gas phase and are, therefore, almost free of these components.

The specific surface area of oil cenospheres and soot were both quite low (Table 4). In the case of the oil cenospheres,

Table 4. BET Specific Surface Area and TGA Reactivity of Secondary Solids from Liquid Feed Experiments

$\begin{array}{ccc}\text { fuel } & \begin{array}{c}\text { BET specific surface area, } \\ \mathrm{m}^{2} / \mathrm{g}\end{array} & \begin{array}{c}\text { TGA reactivity, } r_{\mathrm{m}, 50}, \\ 10^{-4} \mathrm{~s}^{-1}\end{array} \\ \begin{array}{c}\text { straw oil } \\ \text { cenospheres }\end{array} & 13 & 4.3 \\ \text { straw oil soot } & 35 & 0.1\end{array}$

this may be explained by the shell forming process from increasingly heavy tar components which solidify and create a solid carbon matrix with almost no microporosity (pores $<2$ $\mathrm{nm}$ ). The moderate specific surface area of the oil soot is mainly based on microporosity.

Surprisingly, the reactivity of the oil cenospheres turned out to be in the same order of magnitude as the secondary char particles that were pyrolyzed under the same conditions applying dry feed. Oil cenospheres and soot both are comparable in terms of composition and surface area but very different in reactivity. This might be explained by their entirely different structures caused by their very different mechanisms of formation. The solid product of liquid phase cracking could be imagined as a mostly amorphous structure with many defects while the matrix of soot is created by a more or less ordered arrangement of gaseous precursors. This might explain the drastic differences in reactivity. 

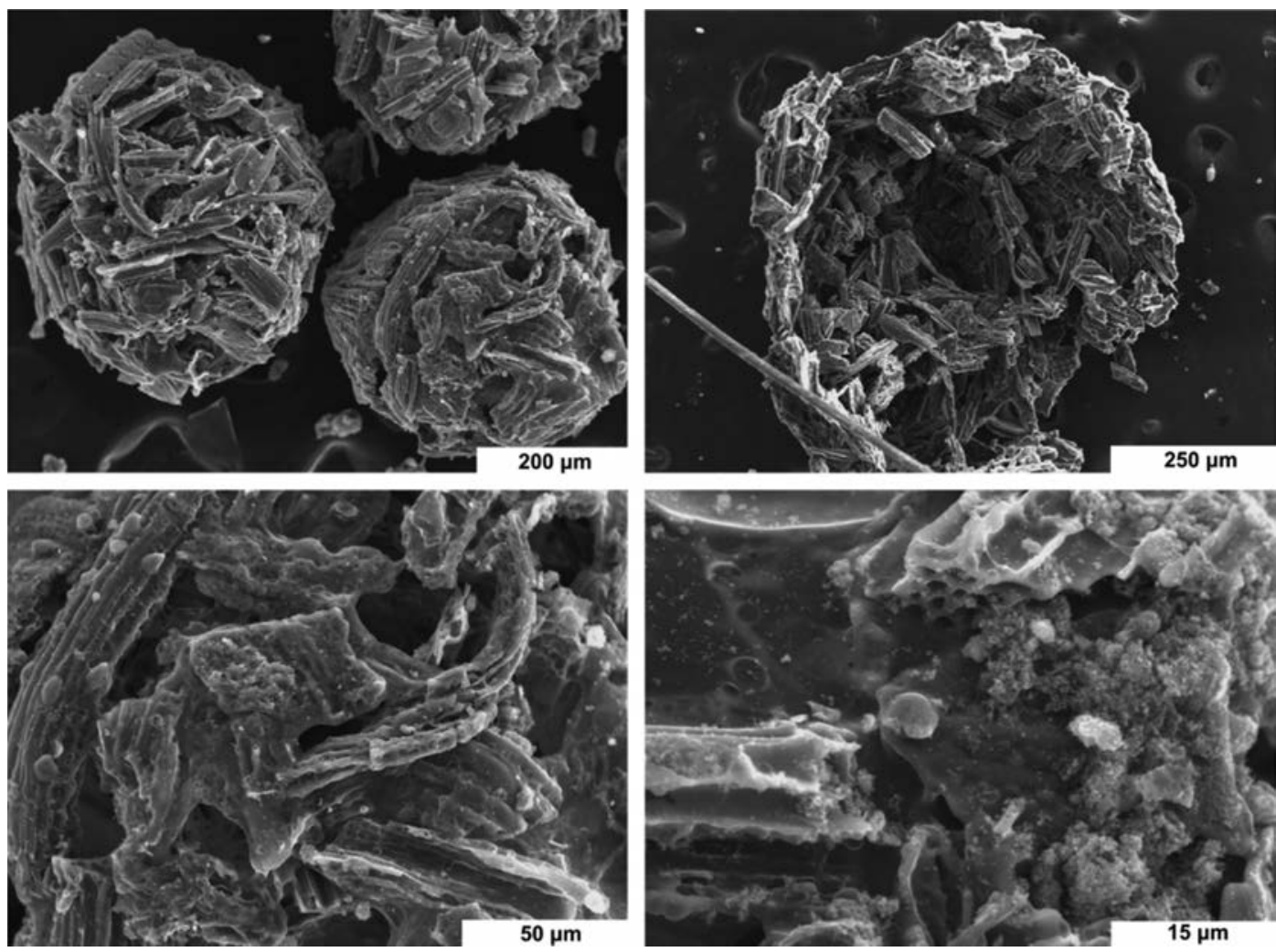

Figure 6. Slurry cenospheres with embedded former primary char, covered with soot. Top left: intact; top right: fractured; bottom: details.

Slurry Feed Experiments. From the slurry feed experi ments, slightly more solids than from the corresponding liquid feed experiment could be recovered. The recovered solid yield of a single slurry feed run was slightly over $23 \mathrm{~m} \%$. If solid yields were not influenced by oil-char interactions, a slurry containing $5.8 \mathrm{~m} \%$ primary solid would result in a theoretical solid yield of $23.5 \mathrm{~m} \%$ ( $60 \mathrm{~m} \%$ for solid feed and $20 \mathrm{~m} \%$ for oil feed). This suggests that the solid yield may not have been strongly influenced by liquid-solid interactions and could be seen more as a function of pyrolysis conditions. Unlike suggested in the literature, ${ }^{14}$ catalytic cracking of bio oil by the ash components of the primary char in slurry seems to have played a minor role. Further investigations on this part are required. Similar to the solids collected from the liquid feed experiments, the solids from slurry feed consisted of two different fractions: spherical secondary char particles and soot. Water and tar contents as well as the composition of permanent gases were comparable to the corresponding liquid feed experiments.

Similarly to the liquid feed experiments, Figure 6 (top) shows the secondary char to also be cenospheres. These consisted of former primary char particles embedded in the outer shell of the further called slurry cenospheres. Their diameter was comparable to the range found in the corresponding liquid feed experiments. The former primary char particles were held together by newly created char from liquid phase cracking, acting as a binder. In most particles, the newly created solid covered virtually the entire surface (Figure 6 , bottom left). In some cases, the former primary char particles looked like they were once floating partially submerged on the surface of a liquid which was then solidifying, trapping all particles in its structure (Figure 6, bottom right). One should notice that, in this image, the flat surface in the upper left corner is not the surface of the sample holder but actually the surface of the cenosphere material. As can be seen, the former primary char particles are fully embedded into the cenosphere structure. Similarly to liquid feed experiments, the outer surfaces of the cenospheres were partially covered with soot, which may be attributed to particle collection. No inorganic matter was detected inside the carbon coating believed to stem from liquid phase cracking by means of EDX. Ash components were restricted to the former primary char areas. Individual former primary char particles not embedded in sphere structures were not observed, suggesting that primary char particles inside the slurry feed were not able to escape the droplets.

The process of slurry cenosphere formation may be explained as follows: As the temperature of the droplet during heat up is rapidly increasing, the suspended primary particles are driven outward toward the droplet surface due to convection caused by internal evaporation of low boiling oil components and water. Once at the droplet surface, the char particles cannot escape the liquid phase since the forces that tie it to the liquid phase are strong enough to contain them. As the temperature of the outer droplet surface further increases due to high gas phase temperatures and intensive radiation, a portion of the cracking oils at the surface are continuously growing in molecular size and viscosity until they reach a state which is solid at ambient conditions, trapping the former primary char particles into their hollow shell.

To the authors' knowledge, this effect of pyrolysis oil and char interaction has not been reported in the literature before.

Comparative Gasification Study of Secondary Solids. To further characterize the secondary solids from the drop tube pyrolysis experiments, a comparative study of selected fuels was carried out comprised of all straw based products: secondary 
straw char, straw oil cenospheres, straw oil soot, and straw slurry cenospheres. TG measurements were conducted according to the reactivity analysis procedure described in section 2 .

Because of experimental limitations in the case of the slurry drop tube experiments, insufficient mixing of the slurry feed was likely to cause a variation in concentration of primary char particles inside the droplets. As a result, the slurry cenospheres found showed a wide range of former primary char particles versus mass of newly created secondary char formed by liquid phase cracking. In contrast to the slurry cenospheres shown in Figure 6, the solid products of slurry were also composed of cenospheres having a much lower former primary char particle content. These cenospheres looked similar to oil cenospheres but only had a small number of former primary char particles embedded in their shells. The straw slurry cenospheres used in this study were the heavier fraction of cenospheres found inside the solid sample of the slurry experiments with a high content of primary char.

Table 5 shows volatile and ash contents of the selected secondary solids derived from TG experiments. The straw oil

Table 5. Volatile and Ash Contents of Selected Secondary Solids

\begin{tabular}{lcc}
\multicolumn{1}{c}{ solid } & volatiles, $\mathrm{m} \% \mathrm{mf}$ & ash, $\mathrm{m} \% \mathrm{mf}$ \\
\hline secondary straw char & 8 & 15 \\
straw oil cenospheres & 21 & $<0.1$ \\
straw oil soot & 3 & $<0.1$ \\
straw slurry cenospheres & 16 & 6
\end{tabular}

cenospheres had the highest amount of volatile matter, which can be explained by their matrixes being composed of highly reactive, heavy tar components which seem to be able to pyrolyze even further during the long residence time of TGA heat up. This supports the assumption that the pyrolysis of the oil cenosphere material was not complete by the time these products were quenched in the drop tube experiment. Soot, on the other hand, had by far the lowest amount of volatiles. A part of it might stem from contamination with fragments of cenosphere material since their separation was not ideal. This is also supported by the fact that, after switching to the gasification agent $\mathrm{CO}_{2}$ in the TG experiment, the otherwise very slow soot conversion curve showed a brief moment of high reactivity.

As mentioned above, there was a wide range of different slurry cenosphere fractions with different former primary char loadings. In this comparative study, volatiles and ash of slurry cenospheres studied suggest a former primary char content of approximately $40 \mathrm{~m} \%$ based on calculations with values from Table 5 and the assumption that the solid yield of slurry is proportional to the yields determined in dry and oil feed experiments. The nonideal experimental behavior of varying solid content of the fed slurry generates the additional information that the effect of formation of slurry cenospheres seems to occur in a very wide range of slurry solid contents and is not restricted to the solid contents originally designed for this experiment.

A conversion-over time graph of the TG measurements is shown in Figure 7. It can be seen that all secondary solids show similar conversion rates up to approximately $50 \%$ conversion with the exception of oil soot, which clearly reacts more than 1 order of magnitude slower. While the secondary straw char is

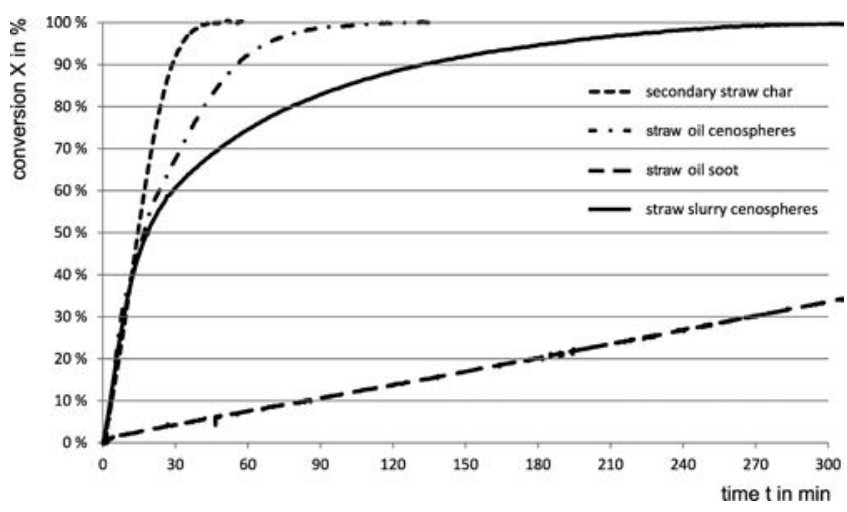

Figure 7. Conversion over time of selected secondary solids. $900{ }^{\circ} \mathrm{C}$, $10 \mathrm{v} \% \mathrm{CO}_{2}$ in $\mathrm{N}_{2}$.

able to maintain its initial conversion rate, cenospheres from oil and especially from slurry experience a significant deceleration of the conversion rate. At this point, the effect responsible for this behavior is not understood. In the case of the oil cenospheres, a possible explanation could be that the carbon matrix is composed of different types of carbon having different reactivities. Additional TG measurements which show a nonuniform ratio between materials of high and low reactivity in oil cenospheres further support this theory. The volatile content of oil cenospheres increases when a larger ratio of reactive to unreactive material was observed, which might indicate the presence of a wide range of high molecular tars with the lighter ones giving more volatiles and a higher reactivity. In the case of the slurry cenospheres, the leveling off of the conversion curve at conversions over $50 \%$ might be explained by the same effect that was discussed for the oil cenospheres. This might be the case since the slurry cenospheres are likely to also be composed of similar types of carbon formed by liquid phase cracking. Another explanation might be the plugging of pores of former primary char particles by the carbon coating. At this point, additional investigations are required.

In an attempt to better understand the conversion behavior of cenosphere structures, both straw oil cenospheres as well as straw slurry cenospheres were subjected to the same TG procedure that was described earlier but were quenched after a conversion of approximately $20 \%$.

The result of the partial conversion of the oil cenospheres is shown in Figure 8. The heterogeneous conversion is

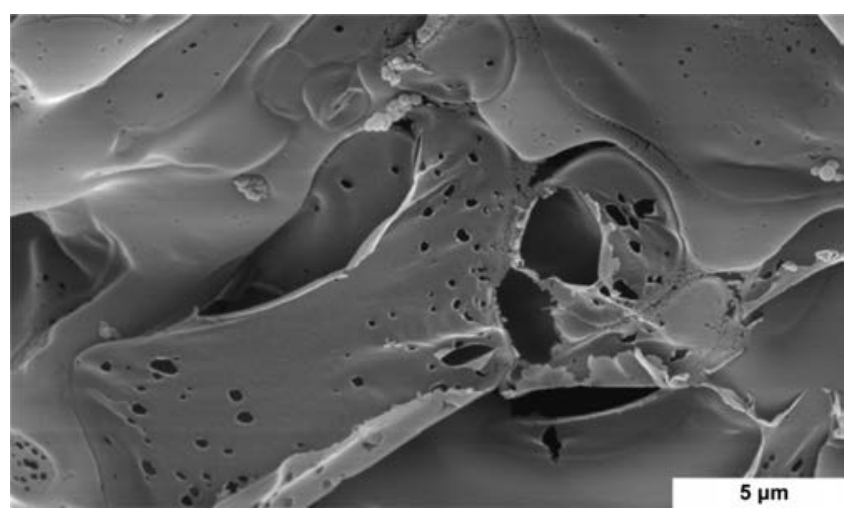

Figure 8. Straw oil cenosphere, partially gasified in $\mathrm{CO}_{2}$ by TGA $(X=$ $20 \%)$. 
accompanied by a detachment of the thin carbon film from the original sphere structure (Figure 4). Besides the reactive chemistry of the oil cenosphere material, this effect might also contribute to the observed high conversion rates (Figure 7). Although without noteworthy microporosity and thus surface area (Table 4), due to the observed detachment of thin layers, the surface of oil cenospheres seem to have a high accessibility.

In the case of the straw slurry cenospheres which were also quenched at approximately $20 \%$ conversion inside the TGA, some particles were found which seemed to have reacted nonuniformly. These results give new insight into possible stages of slurry char conversion. In Figure 9, three main zones

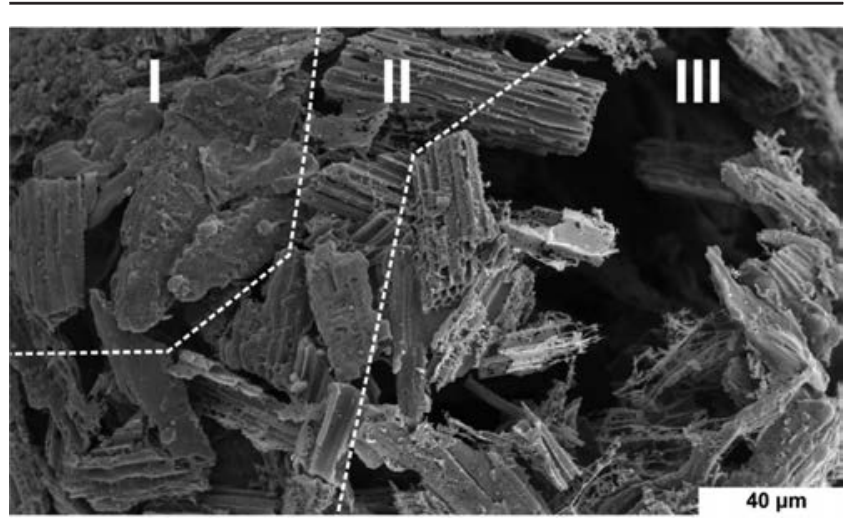

Figure 9. Straw slurry cenosphere, partially gasified in $\mathrm{CO}_{2}$ by TGA ( $X$ $=20 \%$ ).

can be identified: At the beginning of the reaction, the former primary char particles are still entirely embedded in novel char from liquid phase cracking (I). As the conversion increases, the former primary char particles are first decoated (II) and are then fully converted by further reaction (III).

\section{SUMMARY AND CONCLUSIONS}

An investigation of the secondary pyrolysis of biomass based slurry was carried out. The focus was set on the solid products of secondary pyrolysis in an entrained flow gasification process, their characterization, the mechanisms of formation, and subsequent conversion behavior.

Bark free softwood chips and chopped wheat straw were fed to a screw pyrolysis reactor at $500{ }^{\circ} \mathrm{C}$ for $300 \mathrm{~s}$ to produce corresponding primary chars and pyrolysis oils used as feedstocks for this study. These four fuels were further treated and characterized. A slurry was prepared composed of primary straw char and its corresponding straw oil.

The five fuels were fed to a drop tube reactor to study their secondary pyrolysis at $1200{ }^{\circ} \mathrm{C}$ for 3 s. To gain a better understanding of secondary slurry pyrolysis, the two primary chars as well as the two primary oils were also investigated individually under the same conditions as the slurry.

The dry feed experiments with both chars resulted in secondary chars. Approximately $60 \mathrm{~m} \%$ of the feed could be recovered as solids. These solids showed no microscopic changes besides edges being slightly rounded off. The carbon content of both secondary chars was increased; the specific surface areas increased by about a factor of 10 . The reactivity of the secondary wood char remained unchanged. The drastic loss of reactivity for the secondary straw char is believed to be caused by the loss of catalytically active ash components such as potassium whose concentration was drastically reduced by the pyrolysis conditions. Ash loss is also indicated by decreased ash contents of the secondary straw char. The silica part of the ash seemed to have bound the remaining potassium, further reducing catalytic effects by thermal deactivation. The secondary straw char showed reactivity close to the one of the secondary wood char, which suggests that most of the catalytic sites might have been lost or deactivated.

The liquid feed experiments with both oils resulted in a solid yield of approximately $20 \mathrm{~m} \%$. Cenospheres and soot were identified. The oil cenospheres consisted of highly carbon containing hollow spheres with diameters close to the former droplet diameters. The oil cenospheres and soot had a similar chemical composition and specific surface areas but showed very different reactivities, which may be explained by their different structures. While the chemical composition and volatile content of the oil cenospheres suggest that these were most probably formed by liquid phase cracking of heavy oil components, the observed soot was formed by polymer ization reactions from the gas phase, creating a very different solid with very low reactivity.

The slurry feed experiments showed similar results as the liquid feed experiments with the important exception of former primary char particles being embedded in the outer carbon shell. These particles showed signs of having undergone almost the same pyrolysis as in dry feed but were heavily covered by newly created char from liquid phase cracking. It was shown that slurry cenospheres can form within a wide range of primary char contents inside the feed. Individual former primary char particles not embedded in sphere structures were not observed, suggesting that primary char particles inside the slurry feed were not able to escape the droplets. To the authors' knowledge, the formation of slurry cenospheres by secondary pyrolysis of biogenic slurry has not been reported in the literature before.

In order to study the conversion behavior of the produced secondary solids, additional TG measurements were carried out applying secondary straw char, straw oil cenospheres, straw oil soot, and straw slurry cenospheres. The oil soot showed the by far lowest reactivity. The other fuels showed similar fast conversion rates up to approximately 50\%. At higher conversions, the rates of oil cenopheres and especially slurry cenospheres leveled off significantly. To better understand the complex conversion behavior, an additional study showed different phases of oil and slurry cenosphere conversion. Further investigations may be required to describe slurry cenosphere formation and conversion in more detail.

\section{AUTHOR INFORMATION}

\section{Corresponding Author}

*E mail: thomas.kolb@kit.edu. Phone: +49 72160842560.

\section{Notes}

The authors declare no competing financial interest.

\section{ACKNOWLEDGMENTS}

The authors gratefully acknowledge financial support from Alberta Innovates EES and the Helmholtz Association of German Research Centers through the Helmholtz Alberta Initiative as well as the Helmholtz Virtual Institute for Gasification Technology. 


\section{NOMENCLATURE}

\section{Abbreviations}

AAEM = alkaline and alkaline earth metals

BET $=$ Brunauer, Emmett, and Teller

BSE $=$ backscattered electrons

$\mathrm{EA}=$ elemental analysis

EDX $=$ energy dispersive $\mathrm{X}$ ray spectroscopy

$\mathrm{EFG}=$ entrained flow gasification

$\mathrm{GC}=$ gas chromatograph

$\mathrm{HAI}=$ Helmholtz Alberta Initiative

KIT $=$ Karlsruhe Institute of Technology

$\mathrm{SE}=$ secondary electrons

SEM = scanning electron microscopy

SMD $=$ Sauter mean diameters

TEM $=$ transmission electron microscopy

$\mathrm{TG}=$ thermogravimetric

TGA $=$ thermogravimetric analyzer

\section{Subscripts:}

$r_{\mathrm{m}, 50}=$ reactivity at a conversion of $50 \%$

\section{REFERENCES}

(1) Higman, C. State of the Gasification Industry: The Updated Worldwide Gasification Database. In 2013 Gasification Technologies Conference Presentations, Colorado Springs, CO, Oct 13-16, 2013; GSTC: Arlington, VA, 2013; p 288 .

(2) Kolb, T.; Eberhard, M. BtL The bioliq Process at KIT. In DGMK International Conference: New Technologies \& Alternative Feedstocks in Petrochemistry and Refining, DGMK Conference Proceedings, Dresden, Germany, Oct 9-11, 2013; DGMK: Berlin, 2013

(3) Dahmen, N.; Dinjus, E.; Kolb, T.; Arnold, U.; Leibold, H.; Stahl, R. Environ. Prog. Sustainable Energy 2012, 31, 176-181.

(4) Scholz, R.; Beckmann, M.; Pieper, C.; Muster, M.; Weber, R. Renewable Sustainable Energy Rev. 2014, 35, 109-125.

(5) Mancini, M.; Weber, R.; Weigand, P.; Leuckel, W.; Kolb, T. Design of the Entrained Flow Reactor for Gasification of Biomass Based Slurry. In 26. Deutscher Flammentag Verbrennung und Feuerung, Duisburg, Germany, Sept 11-12, 2013; VDI Berichte 2161, VDI Verlag GmbH: Düsseldorf, Germany, 2013; pp 625-634.

(6) Kolb, T.; Aigner, M.; Kneer, R.; Müller, M.; Weber, R.; Djordjevic, N. J. Energy Inst. Article in Press. DOI:10.1016/ j.joei.2015.07.007.

(7) Mueller, A.; Haustein, H.; Stoesser, P.; Kreitzberg, T.; Kneer, R.; Kolb, T. Energy Fuels 2015, 29, 6717-6723.

(8) Sänger, A.; Kolb, T.; Mancini, M.; Weber, R.; Weigand, P. The Bioliq Entrained Flow Gasifier for Biomass Based Slurry - Design and Operation. In Proceedings of the 38th International Conference on Clean Coal \& Fuel Systems, Clearwater, FL, June 2-6, 2013; Curran Associates Inc.: Red Hook, NY, USA.

(9) Senneca, O.; Salatino, P.; Masi, S. Fuel 1998, 77, 1483-1493.

(10) Ahmed, I. I.; Gupta, A. K. Appl. Energy 2011, 88, 1613-1619.

(11) Wu, H.; Yu, Y.; Yip, K. Energy Fuels 2010, 24, 5652-5659.

(12) Gao, W.; Zhang, M.; Wu, H. Fuel 2016, 176, 72-77.

(13) Ghezelchi, M. H.; Garcia Perez, M.; Wu, H. Energy Fuels 2015, $29,8058-8065$.

(14) Chhiti, Y.; Salvador, S.; Commandre, J.; Broust, F.; Couhert, C. Energy Fuels 2011, 25, 345-351.

(15) Whitty, K.; Backman, R.; Hupa, M. Bioresour. Technol. 2008, 99, 663-670.

(16) Oasmaa, A.; Leppämäki, E.; Koponen, P.; Levander, J.; Tapola, E. Physical characterisation of biomass based pyrolysis liquids: Application of standard fuel oil analysis; VTT Publications: Espoo, Finland, 1997; No. 306.

(17) Zhang, L.; Xu, C. C.; Champagne, P. Energy Convers. Manage. 2010, 51, 969-982.

(18) Tomasi Morgano, M.; Leibold, H.; Richter, F.; Seifert, H. J. Anal. Appl. Pyrolysis 2015, 113, 216-224.
(19) Sipilae, K.; Kuoppala, E.; Fagernaes, L.; Oasmaa, A. Biomass Bioenergy 1998, 14, 103-113.

(20) Shaddix, C. R.; Hardesty, D. R. Combustion Properties of Biomass Flash Pyrolysis Oils: Final Project Report; Report No. SAND99-8238; Sandia National Laboratories: Albuquerque NM, 1999.

(21) García Pérez, M.; Lappas, P.; Hughes, P.; Dell, L.; Chaala, A.; Kretschmer, D.; Roy, C. IFRF Combust. J. 2006, 200601.

(22) Lu, Q.; Yang, X. 1.; Zhu, X. f. J. Anal. Appl. Pyrolysis 2008, 82, 191-198.

(23) García Pérez, M.; Chaala, A.; Pakdel, H.; Kretschmer, D.; Rodrigue, D.; Roy, C. Energy Fuels 2006, 20, 364-375.

(24) Vejahati, F.; Katalambula, H.; Gupta, R. Energy Fuels 2012, 26, 219-232.

(25) Jordan, A. C.; Akay, G. Biomass Bioenergy 2012, 42, 51-58.

(26) Dahlquist, E. Technologies for Converting Biomass to Useful Energy: Combustion, Gasification, Pyrolysis, Torrefaction and Fermenta tion; CRC Press: Boca Raton, FL, 2013.

(27) Berahman, B. A Preliminary Study on Pyrolysis and Gasification of Asphaltenes and coal asphaltenes slurry in an entrained flow reactor. M.Sc. Thesis, University of Alberta, Edmonton, AB, Canada, 2012.

(28) Di Blasi, C. Prog. Energy Combust. Sci. 2009, 35, 121-140.

(29) Septien, S.; Valin, S.; Dupont, C.; Peyrot, M.; Salvador, S. Fuel 2012, 97, 202-210.

(30) Misra, M. K.; Ragland, K. W.; Baker, A. J. Biomass Bioenergy 1993, 4, 103-116.

(31) Kannan, M. P.; Richards, G. N. Fuel 1990, 69, 747-753.

(32) Urban, D. L.; Dryer, F. L. New results on coke formation in the combustion of heavy fuel droplets. In Proceedings of the Combustion Institute, 23th International Symposium on Combustion, University of Orléans, Orléans, France, July 22-27, 1990; The Combustion Institute/Elsevier: Amsterdam, 1990; pp 1437-1443.

(33) Wissmiller, D. Pyrolysis oil combustion characteristics and exhaust emissions in a swirl stabilized flame. Ph.D. Thesis, Iowa State University, Ames, Iowa, 2009.

(34) Wornat, M. J.; Porter, B. G.; Yang, N. Y. C. Energy Fuels 1994, 8, $1131-1142$.

(35) Xi, J.; Zhong, B. J. Chem. Eng. Technol. 2006, 29, 665-673. 
Karlsruher Institut für Technologie

\section{Repository KITopen}

Dies ist ein Postprint/begutachtetes Manuskript.

Empfohlene Zitierung:

Stoesser, P.; Ruf, J.; Gupta, R.; Djordjevic, N.; Kolb, T.

Contribution to the Understanding of Secondary Pyrolysis of Biomass-Based Slurry under Entrained-Flow Gasification Conditions.

2016. Energy \& fuels, 30

doi:10.5445/IR/1000060031

Zitierung der Originalveröffentlichung:

Stoesser, P.; Ruf, J.; Gupta, R.; Djordjevic, N.; Kolb, T.

Contribution to the Understanding of Secondary Pyrolysis of Biomass-Based Slurry under Entrained-Flow Gasification Conditions.

2016. Energy \& fuels, 30 (8), 6448-6457

doi:10.1021/acs.energyfuels.6b00935 